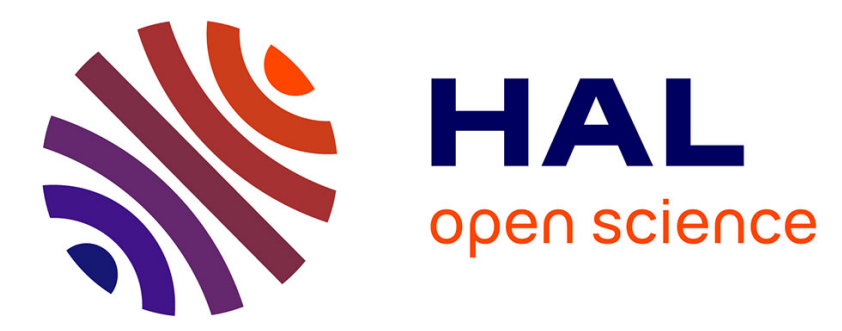

\title{
Control Strategies for Non-sinusoidal Multiphase PMSM Drives in Faulty Modes under Constraints on Copper Losses and Peak Phase Voltage
}

Duc Tan Vu, Ngac Ky Nguyen, Eric Semail, Tiago Jose dos Santos Moraes

\section{- To cite this version:}

Duc Tan Vu, Ngac Ky Nguyen, Eric Semail, Tiago Jose dos Santos Moraes. Control Strategies for Non-sinusoidal Multiphase PMSM Drives in Faulty Modes under Constraints on Copper Losses and Peak Phase Voltage. IET Electric Power Applications, 2019, pp.11. hal-02147428

\author{
HAL Id: hal-02147428 \\ https://hal.science/hal-02147428
}

Submitted on 4 Jun 2019

HAL is a multi-disciplinary open access archive for the deposit and dissemination of scientific research documents, whether they are published or not. The documents may come from teaching and research institutions in France or abroad, or from public or private research centers.
L'archive ouverte pluridisciplinaire HAL, est destinée au dépôt et à la diffusion de documents scientifiques de niveau recherche, publiés ou non, émanant des établissements d'enseignement et de recherche français ou étrangers, des laboratoires publics ou privés. 


\title{
Control Strategies for Non-sinusoidal Multiphase PMSM Drives in Faulty Modes under Constraints on Copper Losses and Peak Phase Voltage
}

\author{
Duc Tan Vu*, Ngac Ky Nguyen, Eric Semail, Tiago Jose dos Santos Moraes \\ Univ. Lille, Arts et Metiers ParisTech, Centrale Lille, HEI, EA 2697 - L2EP - Laboratoire d'Electrotechnique et \\ d'Electronique de Puissance, F-59000 Lille, France \\ *ductan.vu@ensam.eu
}

\begin{abstract}
In the context of future Permanent Magnet Synchronous Machines (PMSMs) with a high number of phases (>7) in integrated drives, this paper proposes several control strategies when multiphase PMSMs with non-sinusoidal back electromotive forces (back-EMFs) operate in healthy and open-circuit faults. In all operation modes, the considered constraint on current is related to the maximum root mean square (RMS) current allowable in one phase of the machine. The constraint on voltage limits the maximum peak value of the phase voltage determined by the DC-bus voltage of the converter. When one or two phases are opencircuited, to maximize torque and respect the constraints, new current references obtained by several proposed methods in rotating and natural frames are imposed to the machine. Due to the non-sinusoidal waveform of back-EMFs and the considered constraints, numerical computations based on analytical formulations are required to obtain maximal torque-speed characteristics, including the flux-weakening operation. The usefulness of the proposed strategies is verified by numerical and experimental results.
\end{abstract}

\section{Introduction}

Variable-speed electric drives using multiphase machines have been known for a half of century. The interest in this area has been growing significantly during the last decade because of developments in some specific application areas (ship propulsion, traction and aircraft) and the evolution of technology. Better fault-tolerance from faults of the power converters and the ability to reduce per phase converter rating are the main advantages of the multiphase machines compared with the conventional three-phase machines $[1,2]$. The summary of recent designs, modelling and control methods of multiphase machines in healthy and faulty modes is presented and analysed in $[3,4]$. To reconfigure the control in degraded modes, fault information needs to be provided. Therefore, there has been one original idea for fault detections as presented in $[5,6]$ by exploiting specificities of the multiphase drives.

In contrary to three-phase machines, it is easy, with multiphase PM machines, to develop vector controls with low torque ripples even with non-sinusoidal electromotive forces. More precisely, considering the multi-reference frames or equivalent Multi-Machine approach [7], the control is simple if only one harmonic of the back-EMF presents in each d-q frame. Therefore, with machines having an odd number of phases $n$, the back-EMF can contain $(n+1) / 2$ odd harmonics. For example, with 11 phases, six odd harmonics are admissible. Increasing the number of phases allows decreasing the constraints on the design of the rotor and also of the windings. It is particularly important to the new generation of PM machines with tooth concentrated windings. These machines are studied for the mass-market field of electrified automotive industry mainly because of lower manufacturing costs and shorter end-windings [8-10]. In the past, a high number of phases (such as $12,13,15$ or more) were found only for high power systems (>1MW) such as marine applications [11]. Nowadays, with the emergence of integrated drives for automotive applications, drive systems with the high number of phases are appearing [10, 12]. For the control, the higher number of phases is not a strong constraint in normal condition. For example, with a 9phase machine, four $\mathrm{d}-\mathrm{q}$ frames are considered. However, considering faulty modes of a drive with a high number of phases leads to a constraint of calculations. Moreover, for traction payload, the nonlinear constraint such as maximum peak voltage in the flux-weakening operation needs to be considered.

The purpose of the paper is to propose control strategies in fault operations and under constraints. These methods are applied to a high number of phases and nonsinusoidal back-EMFs. An experimental test bench with a seven-phase PM machine with non-sinusoidal back-EMFs is used to verify the proposed strategies. In a particular case, the strategies can be extended for a higher number of phases.

In the past, many strategies have been proposed for fault-tolerant control, determining appropriate current references when one or more phases of the machines are open-circuited. Authors in [13] proposed different control strategies for sinusoidal machines having odd or even numbers of phases with an opened phase. New current references in degraded modes ensure the same rotating magnetic field as in healthy mode. However, the voltage limit during the flux-weakening operation has not been considered. In another study, a variable speed control method in [14] considering voltage and current limits is applied to a 5-phase PM synchronous generator under healthy and faulty conditions, including flux-weakening operation. As [13], the strategy in [14] is only introduced for sinusoidal back-EMF machines.

In fault mode operations, several studies based on reduced-order Concordia transformation matrices have been proposed in recent years. These methods are based on the concept of preserving values of magnetomotive forces (MMFs) under single and double-phase open-circuit faults. Methods in [15-20] only deal with sinusoidal back-EMF machines. Therefore, if these methods are applied to the machines with non-sinusoidal back-EMFs, torque ripples will be generated. In [21], both the first and the third harmonic current references are injected to a 5-phase trapezoidal backEMF machine to generate ripple-free torques. However, the new current references in rotating frames are not constant, making higher demands for sophisticated current controllers 
at high speed. In addition, experimental results in [21] also present high torque ripples even in healthy mode. Due to different transformation matrices corresponding to each faulty case, an increase in the number of phases and different faulty conditions result in high-cost calculations and code storages. Differently, the present paper intends to use only one generalized Concordia transformation matrix for different faulty cases. Moreover, the strategies in [15-21] have not considered constraints on current and voltage.

In [22-24], the fundamental and third-harmonic current components for the excitation in healthy stator phases are introduced for a 5-phase PMSM with trapezoidal backEMFs in open-circuit faults. The constraint on the RMS current or stator ohmic loss has been considered but the constraint on peak phase voltage for the flux-weakening operation has not been considered. Additionally, in [22-24], there are eight unknown variables in current expressions determined by fmincon function. Thus, by the same way, the higher number of phases of machines results in more variables, making current reference calculations more complicated and less accurate due to the sensitivity of fmincon on the number of variables. In [25], fault-tolerant control strategies for a trapezoidal 7-phase machine using a vectorial multiphase description are verified in single and double phase open-circuit faults. Limitation of total copper losses are considered but the constraint on voltage, as well as flux-weakening operation, have not been considered due to its low-speed applications. Studies in [26, 27] consider minimum global loss or maximum torque for sinusoidalMMF 6-phase induction machines in a single-phase opencircuit fault but the voltage limit is not considered. In [25-27], the adjustments of current references in post-fault operations can produce unequal RMS phase currents if the global loss limits are considered. Some of the resulting phase currents can get higher than their rated value. Although considering constraints on current and voltage, strategies in [28, 29] apply online computations of current reference generation, which can be a big challenge in the real-time systems with a higher number of phases. As [29], another study using model predictive control is presented in [30] for six-phase PMSM drives with sinusoidal back-EMFs and currents. In [30], the total copper losses of all healthy phases are optimized, resulting in the overrated RMS current problem as in [25-27]. In [31], the control strategies have been presented and validated by numerical results for a trapezoidal back-EMF 7phase PM machine with two identical rotors. Notably, the constraints on peak phase current and peak phase voltage have been considered.

This paper, as an expansion of [31], presents different control strategies for multiphase machines with nonsinusoidal back-EMFs in healthy and faulty modes. The torque-speed characteristics are optimized under constraints. The constraints on copper loss per phase (according to the local thermal limit) and peak phase voltage (limitation of the Voltage Source Inverter (VSI)) are strictly respected. Thus, the machine can operate in the flux-weakening region even in faulty modes without overheating any phase windings. Thanks to the offline optimization process, the control methods are easy to implement in real-time applications. These methods can be applied to machines with a high number of phases. The proposed strategies are experimentally verified in a non-sinusoidal 7-phase axial flux PM machine with two different rotors. In healthy mode, the first, third and ninth harmonic components of current and back-EMF are considered to generate torques. In degraded modes, due to a decrease in Degree of Freedom (DoF), only the first and third harmonics in the rotating frames are determined as constants. The details of use of harmonic components will be analysed in next sections. In case of single-phase open-circuit faults, four different methods are introduced. When two phases are open-circuited, a method determining the first and third harmonics of current references in rotating frames is presented.

The paper is organized as follows: Section 2 describes the modelling of the considered machine. The control strategies for different operating modes are presented in section 3. Sections 4 gives numerical and experimental results.

\section{Multi-phase machine modelling}

The design of a 7-phase PM machine is proposed in $[32,33]$ with axial flux and double identical rotors. In this study, a 7-phase PM machine with two-different rotors are considered, resulting in an asymmetrical non-sinusoidal waveform of back-EMFs as shown in Fig. 1. These following assumptions are considered to model the machine: 7 phases of the machine are equally shifted and wye-connected; the saturation of the magnetic circuits is not considered in the calculations of the back-EMFs and the fluxes; impacts of iron losses are not considered in this study. The voltage vector and torque can be written as follows:

$\overrightarrow{\boldsymbol{v}}=R \overrightarrow{\boldsymbol{\imath}}+[\boldsymbol{\Lambda}] \frac{d \overrightarrow{\boldsymbol{\imath}}}{d t}+\overrightarrow{\boldsymbol{e}}$

$T_{m}=\frac{\overrightarrow{\boldsymbol{e}} \cdot \overrightarrow{\boldsymbol{\imath}}}{\Omega}$

where $\overrightarrow{\boldsymbol{v}}, \overrightarrow{\boldsymbol{\imath}}$ and $\overrightarrow{\boldsymbol{e}}$ are 7-dimensional stator voltage, current and back-EMF vectors respectively; $R$ is the stator resistance of each phase; $[\Lambda]$ is a 7 by 7 stator inductance matrix; $T_{m}$ and $\Omega$ are the torque and rotating speed of the machine.

Concordia and Park transformations are applied to convert respectively the machine into $\alpha-\beta$ and $d-q$ frames. In these frames, the 7-phase machine is equivalent to 3 fictitious 2-phase machines (FM1, FM2, FM3) and 1 zero-sequence machine (ZM) [7, 34]. The fictitious machines are associated to given groups of harmonic components as shown in Table 1 (only in healthy mode). Since the machine windings are wye-connected, the zero-sequence machine is not considered in this study.

\section{Control strategies with constraints on RMS current and peak voltage}

\subsection{Healthy mode}

The machine under this study has a non-sinusoidal back-EMF as shown in Fig. 1. The $3^{\text {rd }}$ and $9^{\text {th }}$ harmonics of the back-EMF account for the highest proportions since their amplitudes are equal to $32.2 \%$ and $12.5 \%$ of the fundamental harmonic respectively. Proportions of other harmonics are smaller $\left(0.25 \%, 10.3 \%, 5.02 \%\right.$ and $1.98 \%$ for the $5^{\text {th }}, 11^{\text {th }}, 13^{\text {th }}$ and $19^{\text {th }}$ harmonics, respectively). In healthy mode, as described in Table 1 , the $1^{\text {st }}$ and $13^{\text {th }}$ harmonics are associated to the first machine FM1. The $9^{\text {th }}$ and $19^{\text {th }}$ harmonics are in 
Table 1 Fictitious machines and associated harmonics (only odd harmonics) of 7-phase machines

\begin{tabular}{ll}
\hline Fictitious machine & Associated harmonics \\
\hline First machine (FM1) & $1,13,15,27 \ldots 7 * \mathrm{k} \pm 1$ \\
Second machine (FM2) & $5,9,19,23 \ldots 7 * \mathrm{k} \pm 2$ \\
Third machine (FM3) & $3,11,17,25 \ldots 7 * \mathrm{k} \pm 3$ \\
Zero-sequence machine (ZM) & $7,21 \quad \ldots 7 * \mathrm{k}$ \\
\hline
\end{tabular}

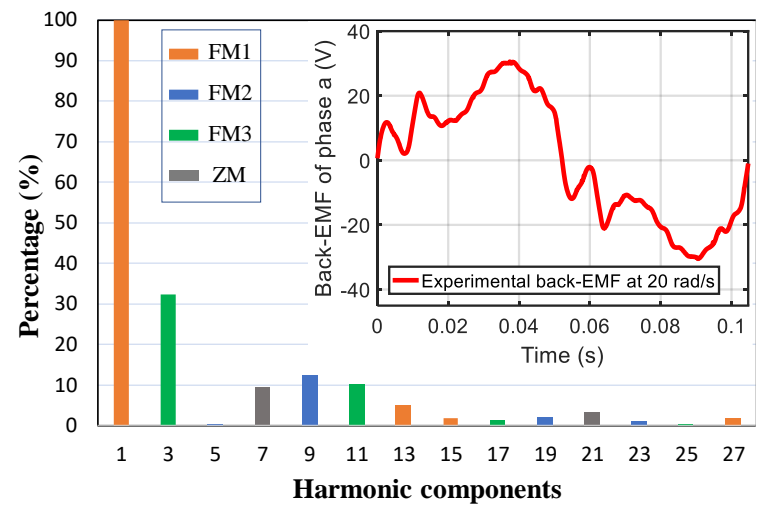

Fig. 1. The waveform and harmonic spectrum of the experimental back-EMF of phase a at 20rad/s

the second machine FM2, and the $3^{\text {rd }}$ and $11^{\text {th }}$ harmonics are in the third machine FM3. In order to impose constant current references in rotating frames when PI controllers are used, only the $1^{\text {st }}, 3^{\text {rd }}$ and $9^{\text {th }}$ harmonic components of current are considered in healthy mode. As a result, using the three harmonics of current leads to torque ripples due to the presence of other high harmonic components of the backEMF. However, since the magnitudes of the other harmonic components are much lower than the three considered ones, torque ripples created by these harmonics are not considered in the optimization strategy. It can be remarked that this assumption is easier to respect when the number of phases increases. The strategy aims at determining constant current references at each speed $\left(i_{d 1}, i_{q 1}, i_{d 9}, i_{q 9}, i_{d 3}, i_{q 3}\right)$ which guarantee the maximum torque and satisfy constraints on current and voltage. Three machines FM1, FM2 and FM3 are independent in healthy mode. Thus, the first, ninth and third harmonics of current are controlled independently. Fmincon function, a nonlinear programming solver to find the minimum of constrained nonlinear multivariable function in MATLAB, is used to determine the current references. These currents are obtained by solving (3).

$\overrightarrow{\boldsymbol{\imath}}=\left([\boldsymbol{T}]^{-1}\right) \overrightarrow{\boldsymbol{\imath}}_{d q}$

where $[\boldsymbol{T}]$ is the transformation matrix in (6); $\theta$ in (6) is the electrical angle; $\overrightarrow{\boldsymbol{\imath}}=\left[\begin{array}{lllllll}i_{a} & i_{b} & i_{c} & i_{d} & i_{e} & i_{f} & i_{g}\end{array}\right]^{T}$ is a current vector

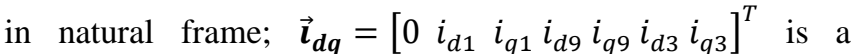
current vector in rotating frames.

In healthy mode, as the system is balanced, only equations for phase $a$ need to be given. On the one hand, the constraint on current can be chosen based on the peak values of phase currents related to Voltage Source Inverter (VSI) components. On the other hand, the constraint on current is also determined according to local or global thermal limits of the stator windings, associated to RMS currents. In this study, the current constraint is chosen to respect the local thermal limit of each machine phase, depending on limiting every RMS phase current, in all operation modes. The limit value of phase voltage is chosen equal to a half of the DC-bus voltage in the Pulse Width Modulation (PWM) technique. Constraints on current and voltage in phase $a$ can be expressed in (4-5).

$$
\begin{aligned}
& I_{R M S a}=R M S\left\{\sqrt{\frac{2}{7}}\left(\begin{array}{c}
i_{d 1} \cos \theta-i_{q 1} \sin \theta+i_{d 9} \cos 9 \theta- \\
-i_{q 9} \sin 9 \theta+i_{d 3} \cos 3 \theta-i_{q 3} \sin 3 \theta
\end{array}\right)\right\} \\
& \leq I_{\max } \\
& \left|v_{a}\right|=\left|\begin{array}{c}
R i_{a}+L \frac{d i_{a}}{d t}+M_{1}\left(\frac{d i_{b}}{d t}+\frac{d i_{g}}{d t}\right) \\
+M_{2}\left(\frac{d i_{c}}{d t}+\frac{d i_{f}}{d t}\right)+M_{3}\left(\frac{d i_{d}}{d t}+\frac{d i_{e}}{d t}\right)+e_{a}
\end{array}\right| \leq V_{\text {max }}
\end{aligned}
$$

where $I_{\max }$ and $V_{\max }$ are the limit values of the RMS current and peak phase voltage; $L$ is the self-inductance of phase $a$; $M_{1}$ is the mutual inductance between phase $a$ and its adjacent phases ( $b$ and $g$ ); $M_{2}$ is the mutual inductance between phase $a$ and its non-adjacent phases displaced by $4 \pi / 7$ ( $c$ and $f$ ); $M_{3}$ is the mutual inductance between phase $a$ and its non-adjacent phases displaced by $6 \pi / 7$ ( $d$ and $e$ ).

\subsection{Single-phase open-circuit faults}

When open-circuit faults happen, it is obviously necessary to have a continuous operation of the drive with an acceptable performance. When one phase is opened, the corresponding current is nullified. It is assumed that an opencircuit fault occurs in phase $a$ and proposed control strategies can be easily adapted for other single-phase open-circuit faults. The current references in healthy mode are unsuitable for faulty cases, hence, they need to be recalculated. In this case, new current references of healthy phases are denoted by $i_{b}^{\prime}, i_{c}^{\prime}, i_{d}^{\prime}, i_{e}^{\prime}, i_{f}^{\prime}$ and $i_{g}^{\prime}$. In faulty conditions, the three fictitious machines in Table 1 are no longer independent. Therefore, only currents in two fictitious machines (the first and third fictitious machines, for example) can be designed and currents in the other machine (the second machine, for example) are the consequences. In order to keep the same control structure as in healthy mode with PI controllers, harmonics of current producing most of the torque need to be

$[\boldsymbol{T}]=\sqrt{\frac{2}{7}}\left[\begin{array}{ccccccc}\frac{1}{\sqrt{2}} & \frac{1}{\sqrt{2}} & \frac{1}{\sqrt{2}} & \frac{1}{\sqrt{2}} & \frac{1}{\sqrt{2}} & \frac{1}{\sqrt{2}} & \frac{1}{\sqrt{2}} \\ \cos \theta & \cos \left(\theta-\frac{2 \pi}{7}\right) & \cos \left(\theta-\frac{4 \pi}{7}\right) & \cos \left(\theta-\frac{6 \pi}{7}\right) & \cos \left(\theta-\frac{8 \pi}{7}\right) & \cos \left(\theta-\frac{10 \pi}{7}\right) & \cos \left(\theta-\frac{12 \pi}{7}\right) \\ -\sin \theta & -\sin \left(\theta-\frac{2 \pi}{7}\right) & -\sin \left(\theta-\frac{4 \pi}{7}\right) & -\sin \left(\theta-\frac{6 \pi}{7}\right) & -\sin \left(\theta-\frac{8 \pi}{7}\right) & -\sin \left(\theta-\frac{10 \pi}{7}\right) & -\sin \left(\theta-\frac{12 \pi}{7}\right) \\ \cos 9 \theta & \cos \left(9 \theta-\frac{4 \pi}{7}\right) & \cos \left(9 \theta-\frac{8 \pi}{7}\right) & \cos \left(9 \theta-\frac{12 \pi}{7}\right) & \cos \left(9 \theta-\frac{16 \pi}{7}\right) & \cos \left(9 \theta-\frac{20 \pi}{7}\right) & \cos \left(9 \theta-\frac{24 \pi}{7}\right) \\ -\sin 9 \theta & -\sin \left(9 \theta-\frac{4 \pi}{7}\right) & -\sin \left(9 \theta-\frac{8 \pi}{7}\right) & -\sin \left(9 \theta-\frac{12 \pi}{7}\right) & -\sin \left(9 \theta-\frac{16 \pi}{7}\right) & -\sin \left(9 \theta-\frac{20 \pi}{7}\right) & -\sin \left(9 \theta-\frac{24 \pi}{7}\right) \\ \cos 3 \theta & \cos \left(3 \theta-\frac{6 \pi}{7}\right) & \cos \left(3 \theta-\frac{12 \pi}{7}\right) & \cos \left(3 \theta-\frac{18 \pi}{7}\right) & \cos \left(3 \theta-\frac{24 \pi}{7}\right) & \cos \left(3 \theta-\frac{30 \pi}{7}\right) & \cos \left(3 \theta-\frac{36 \pi}{7}\right) \\ -\sin 3 \theta & -\sin \left(3 \theta-\frac{6 \pi}{7}\right) & -\sin \left(3 \theta-\frac{12 \pi}{7}\right) & -\sin \left(3 \theta-\frac{18 \pi}{7}\right) & -\sin \left(3 \theta-\frac{24 \pi}{7}\right) & -\sin \left(3 \theta-\frac{30 \pi}{7}\right) & -\sin \left(3 \theta-\frac{36 \pi}{7}\right)\end{array}\right]$


Table 2 Control strategies in single-phase open-circuit faults for non-sinusoidal 7-phase machines

\begin{tabular}{lccc}
\hline Method & $\begin{array}{c}\text { Imposed harmonics } \\
\text { in current references }\end{array}$ & $\begin{array}{c}\text { Design } \\
\text { frame }\end{array}$ & $\begin{array}{c}\text { Allowable } \\
\text { number of } \\
\text { opened phases }\end{array}$ \\
\hline (I) & $1^{\text {st }}\left(\right.$ and $\left.i_{d 3}^{\prime}=i_{q 3}^{\prime}=0\right)$ & $\mathrm{d}-\mathrm{q}$ & 2 \\
(II) & $1^{\text {st }}$ and $3^{\text {rd }}$ & $\mathrm{d}-\mathrm{q}$ & 2 \\
(III) & $1^{\text {st }}$ and $\left.k_{i}=0\right)$ & natural & 4 \\
(IV) & $1^{\text {st }}$ and $3^{\text {rd }}$ & natural & 4 \\
\hline
\end{tabular}

constant in rotating frames. Thus, the first and third harmonics are considered in the following strategies. In this section, four proposed methods as described in Table 2 designing current references in d-q frames (methods (I-II)) and in natural frame (methods (III-IV)) are introduced. The phase currents designed in $\mathrm{d}-\mathrm{q}$ frames have different waveforms and amplitudes. By contrast, the currents imposed in natural frame share the same waveform and amplitude, resulting in identical RMS phase currents. It means that the thermal distributions are equal in all healthy phases. Classifying these methods also allows to see the effects of third harmonics of currents on torque generation. Methods (IIII) using only sinusoidal currents can reduce calculation time. In Table 2, the highest allowable number of opened phases is presented for each method. Indeed, in healthy mode of a wye-connected winding 7-phase machine, DoF for current control is 6 . In faulty modes, with the principle of methods (I-II), 4 constant current references in rotating frames are required. It means that the four currents need to be controllable and DoF must be 4 . Therefore, the number of opened phases in methods (I-II) must not exceed 2. With the principle of methods (III-IV), this number is 4 because the current references are imposed in natural frame. Indeed, the minimum number of independent phase currents need to be 2 to create a rotating field. Function fmincon is applied in all proposed methods to determine the current references, maximizing the machine torque and respecting the constraints on current and voltage.

\subsubsection{Determine current references in $d$-q frames:} Equations (7-10) describe relationships between currents in $\mathrm{d}-\mathrm{q}$ and natural frames. Because of the wye-connected windings, new current references are required to respect (11). However, there are only five equations (7-11) while the system has six unknown currents $\left(i_{b}^{\prime}, i_{c}^{\prime}, i_{d}^{\prime}, i_{e}^{\prime}, i_{f}^{\prime}, i_{g}^{\prime}\right)$. This leads to a lack of one equation to calculate the new current references. The study proposes an additional equation as presented in (12) to find current solutions easily. In Table 2, method (I) is when only the first harmonic is used, $i_{d 3}^{\prime}$ and $i_{q 3}^{\prime}$ must be nullified. In case both the first and third harmonics of current are imposed to optimize the torque, we have method (II). The optimization of torque at each rotating speed must satisfy constraints on current and voltage in (13-14).

$$
\begin{aligned}
& i_{d 1}^{\prime}= \\
& \sqrt{\frac{2}{7}}\left\{\begin{array}{c}
i_{b}^{\prime} \cos \left(\theta-\frac{2 \pi}{7}\right)+i_{c}^{\prime} \cos \left(\theta-\frac{4 \pi}{7}\right)+i_{d}^{\prime} \cos \left(\theta-\frac{6 \pi}{7}\right) \\
+i_{e}^{\prime} \cos \left(\theta-\frac{8 \pi}{7}\right)+i_{f}^{\prime} \cos \left(\theta-\frac{10 \pi}{7}\right)+i_{g}^{\prime} \cos \left(\theta-\frac{12 \pi}{7}\right)
\end{array}\right\} \\
& i_{q 1}^{\prime}=\sqrt{\frac{2}{7}}\left\{\begin{array}{c}
-i_{b}^{\prime} \sin \left(\theta-\frac{2 \pi}{7}\right)-i_{c}^{\prime} \sin \left(\theta-\frac{4 \pi}{7}\right)-i_{d}^{\prime} \sin \left(\theta-\frac{6 \pi}{7}\right) \\
-i_{e}^{\prime} \sin \left(\theta-\frac{8 \pi}{7}\right)-i_{f}^{\prime} \sin \left(\theta-\frac{10 \pi}{7}\right)-i_{g}^{\prime} \sin \left(\theta-\frac{12 \pi}{7}\right)
\end{array}\right\}
\end{aligned}
$$

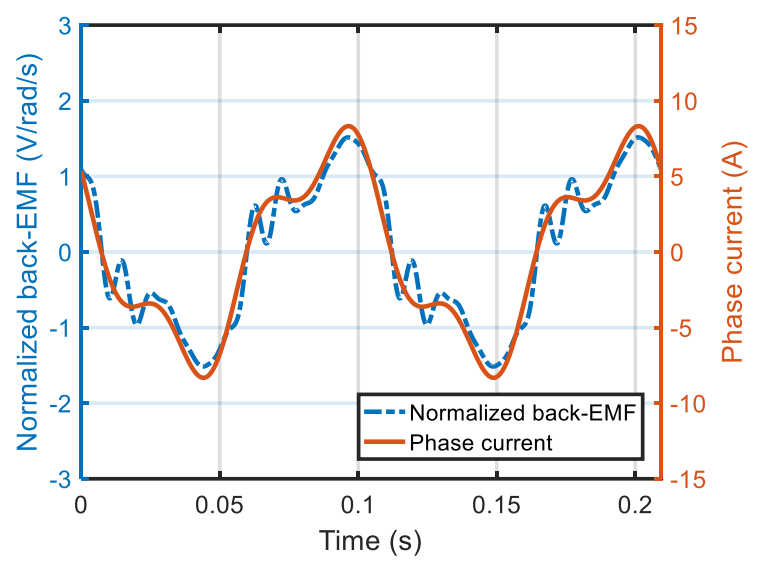

Fig. 2. Experimental speed-normalized back-EMF and current reference of phase e using method (IV) when phase a is opened

$$
\begin{aligned}
& i_{d 3}^{\prime}=\sqrt{\frac{2}{7}}\left\{\begin{array}{c}
i_{b}^{\prime} \cos \left(3\left(\theta-\frac{2 \pi}{7}\right)\right)+i_{c}^{\prime} \cos \left(3\left(\theta-\frac{4 \pi}{7}\right)\right) \\
+i_{d}^{\prime} \cos \left(3\left(\theta-\frac{6 \pi}{7}\right)\right)+i_{e}^{\prime} \cos \left(3\left(\theta-\frac{8 \pi}{7}\right)\right) \\
+i_{f}^{\prime} \cos \left(3 \theta\left(-\frac{10 \pi}{7}\right)\right)+i_{g}^{\prime} \cos \left(3\left(\theta-\frac{12 \pi}{7}\right)\right)
\end{array}\right\} \\
& i_{q 3}^{\prime}=\sqrt{\frac{2}{7}}\left\{\begin{array}{c}
-i_{b}^{\prime} \sin \left(3\left(\theta-\frac{2 \pi}{7}\right)\right)-i_{c}^{\prime} \sin \left(3\left(\theta-\frac{4 \pi}{7}\right)\right) \\
-i_{d}^{\prime} \sin \left(3\left(\theta-\frac{6 \pi}{7}\right)\right)-i_{e}^{\prime} \sin \left(3\left(\theta-\frac{8 \pi}{7}\right)\right) \\
-i_{f}^{\prime} \sin \left(3\left(\theta-\frac{10 \pi}{7}\right)\right)-i_{g}^{\prime} \sin \left(3\left(\theta-\frac{12 \pi}{7}\right)\right)
\end{array}\right\} \\
& i_{b}^{\prime}+i_{c}^{\prime}+i_{d}^{\prime}+i_{e}^{\prime}+i_{f}^{\prime}+i_{g}^{\prime}=0 \\
& i_{b}^{\prime}+i_{d}^{\prime}+i_{f}^{\prime}=0 \\
& R M S\left\{i_{b}^{\prime} ; i_{c}^{\prime} ; i_{d}^{\prime} ; i_{e}^{\prime} ; i_{f}^{\prime} ; i_{g}^{\prime}\right\} \leq I_{\max } \\
& \left\{\left|v_{b}^{\prime}\right| ;\left|v_{c}^{\prime}\right| ;\left|v_{d}^{\prime}\right| ;\left|v_{e}^{\prime}\right| ;\left|v_{f}^{\prime}\right| ;\left|v_{g}^{\prime}\right|\right\} \leq V_{\max }
\end{aligned}
$$

3.2.2. Determine current references in natural frame: New current references in natural frame are shown in (15-20).

$$
\begin{aligned}
& i_{b}^{\prime}=I_{m 1} \sin \left(\omega t+\varphi_{b}+\varphi_{1}\right)+k_{i} I_{m 1} \sin \left(3\left(\omega t+\varphi_{b}+\varphi_{3}\right)\right) \\
& i_{c}^{\prime}=I_{m 1} \sin \left(\omega t+\varphi_{c}+\varphi_{1}\right)+k_{i} I_{m 1} \sin \left(3\left(\omega t+\varphi_{c}+\varphi_{3}\right)\right) \\
& i_{d}^{\prime}=I_{m 1} \sin \left(\omega t+\varphi_{d}+\varphi_{1}\right)+k_{i} I_{m 1} \sin \left(3\left(\omega t+\varphi_{d}+\varphi_{3}\right)\right) \\
& i_{e}^{\prime}=-i_{b}^{\prime} ; i_{f}^{\prime}=-i_{c}^{\prime} ; i_{g}^{\prime}=-i_{d}^{\prime}
\end{aligned}
$$

where $I_{m 1}$ is the peak value of the first harmonic component of phase currents; $k_{i}$ is the ratio of the third over first harmonic of phase currents; $\varphi_{b}, \varphi_{c}$ and $\varphi_{d}$ are constant initial phase angles of phases $b, c$ and $d$ respectively determined by the method in [13]; $\varphi_{1}$ and $\varphi_{3}$ are adjustable angles of the first and third harmonics of phase currents; $\omega$ is the electrical speed of the machine. The proposed current references have the same amplitude with the objective to obtain equal copper losses in the remaining healthy phases as proposed in $[13,14$, 35] for sinusoidal machines. The proposed current references also satisfy the assumption of the wye-connected windings because the sum of all instantaneous currents is zero. If only the first harmonic of phase currents is used, $k_{i}$ is set to zero, we have method (III) in Table 2. Otherwise, method (IV) in Table 2 imposes both the first and third harmonics of currents, the waveform of each heathy phase current is like the speednormalized back-EMF as shown in Fig. 2. This similarity allows the machine to produce the maximum torque (based 
on MTPA). Magnitude $\left(I_{m 1}\right)$, ratio $\left(k_{i}\right)$ and phase angles $\left(\varphi_{1}, \varphi_{3}\right)$ will be determined by function fmincon with the constraints as shown in (13-14). To find the current references in the flux-weakening region, only current magnitude $\left(I_{m 1}\right)$ is allowed to vary because the torque ripples are very sensitive to the changes of the ratio $\left(k_{i}\right)$ and phase angles $\left(\varphi_{1}, \varphi_{3}\right)[36]$.

\subsection{Double-phase open-circuit faults}

Open-circuit faults in two adjacent and non-adjacent phases are considered. In order to keep the same control structure as in healthy mode with PI controllers, the first and third harmonics of current are imposed as constants like method (II) in single-phase open-circuit faults. Current references are calculated by function fmincon with constraints on current and voltage are like the case of single-phase opencircuit faults.

3.3.1. Two adjacent opened phases: Phases $a$ and $b$ are assumed to be open-circuited. New current references of the healthy phases denoted by $\left(i_{c}^{\prime \prime}, i_{d}^{\prime \prime}, i_{e}^{\prime \prime}, i_{f}^{\prime \prime}, i_{g}^{\prime \prime}\right)$ need to satisfy (21-25). Thus, there are 5 equations for 5 unknown currents, hence the solution of currents is unique.

$$
\begin{aligned}
& i_{d 1}^{\prime \prime}= \\
& \sqrt{\frac{2}{7}}\left\{\begin{array}{c}
i_{c}^{\prime \prime} \cos \left(\theta-\frac{4 \pi}{7}\right)+i_{d}^{\prime \prime} \cos \left(\theta-\frac{6 \pi}{7}\right) \\
+i_{e}^{\prime \prime} \cos \left(\theta-\frac{8 \pi}{7}\right)+i_{f}^{\prime \prime} \cos \left(\theta-\frac{10 \pi}{7}\right)+i_{g}^{\prime \prime} \cos \left(\theta-\frac{12 \pi}{7}\right)
\end{array}\right\}(21) \\
& i_{q 1}^{\prime \prime}= \\
& \sqrt{\frac{2}{7}}\left\{\begin{array}{c}
-i_{c}^{\prime \prime} \sin \left(\theta-\frac{4 \pi}{7}\right)-i_{d}^{\prime \prime} \sin \left(\theta-\frac{6 \pi}{7}\right) \\
-i_{e}^{\prime \prime} \sin \left(\theta-\frac{8 \pi}{7}\right)-i_{f}^{\prime \prime} \sin \left(\theta-\frac{10 \pi}{7}\right)-i_{g}^{\prime \prime} \sin \left(\theta-\frac{12 \pi}{7}\right)
\end{array}\right\} \\
& i_{d 3}^{\prime \prime}=\sqrt{\frac{2}{7}}\left\{\begin{array}{c}
i_{c}^{\prime \prime} \cos \left(3\left(\theta-\frac{4 \pi}{7}\right)\right)+i_{d}^{\prime \prime} \cos \left(3\left(\theta-\frac{6 \pi}{7}\right)\right) \\
+i_{e}^{\prime \prime} \cos \left(3\left(\theta-\frac{8 \pi}{7}\right)\right)+i_{f}^{\prime \prime} \cos \left(3 \theta\left(-\frac{10 \pi}{7}\right)\right) \\
+i_{g}^{\prime \prime} \cos \left(3\left(\theta-\frac{12 \pi}{7}\right)\right)
\end{array}\right\} \\
& i_{q 3}^{\prime \prime}=\sqrt{\frac{2}{7}}\left\{\begin{array}{c}
-i_{c}^{\prime \prime} \sin \left(3\left(\theta-\frac{4 \pi}{7}\right)\right)-i_{d}^{\prime \prime} \sin \left(3\left(\theta-\frac{6 \pi}{7}\right)\right) \\
\left.-i_{e}^{\prime \prime} \sin \left(3\left(\theta-\frac{8 \pi}{7}\right)\right)-i_{f}^{\prime \prime} \sin \left(3\left(\theta-\frac{10 \pi}{7}\right)\right)\right) \\
-i_{g}^{\prime \prime} \sin \left(3\left(\theta-\frac{12 \pi}{7}\right)\right)
\end{array}\right\} \\
& i_{c}^{\prime \prime}+i_{d}^{\prime \prime}+i_{e}^{\prime \prime}+i_{f}^{\prime \prime}+i_{g}^{\prime \prime}=0
\end{aligned}
$$

3.3.2. Two non-adjacent opened phases: Due to the regular circular distribution of the phases, there are 2 cases of two non-adjacent opened phases in the 7-phase machine: phases $a$ and $c$ displaced by $4 \pi / 7$; phases $a$ and $d$ displaced by $6 \pi / 7$. When phases $a$ and $c$ are open-circuited, new current references are determined according to (26-30).

$$
i_{d 1}^{\prime \prime}=\sqrt{\frac{2}{7}}\left\{\begin{array}{c}
i_{b}^{\prime \prime} \cos \left(\theta-\frac{2 \pi}{7}\right)+i_{d}^{\prime \prime} \cos \left(\theta-\frac{6 \pi}{7}\right)+i_{e}^{\prime \prime} \cos \left(\theta-\frac{8 \pi}{7}\right) \\
+i_{f}^{\prime \prime} \cos \left(\theta-\frac{10 \pi}{7}\right)+i_{g}^{\prime \prime} \cos \left(\theta-\frac{12 \pi}{7}\right)
\end{array}\right\}
$$

$i_{q 1}^{\prime \prime}=\sqrt{\frac{2}{7}}\left\{\begin{array}{c}-i_{b}^{\prime \prime} \sin \left(\theta-\frac{2 \pi}{7}\right)-i_{d}^{\prime \prime} \sin \left(\theta-\frac{6 \pi}{7}\right)-i_{e}^{\prime \prime} \sin \left(\theta-\frac{8 \pi}{7}\right) \\ -i_{f}^{\prime \prime} \sin \left(\theta-\frac{10 \pi}{7}\right)-i_{g}^{\prime \prime} \sin \left(\theta-\frac{12 \pi}{7}\right)\end{array}\right\}$

$$
\begin{gathered}
i_{d 3}^{\prime \prime}=\sqrt{\frac{2}{7}}\left\{\begin{array}{c}
i_{b}^{\prime \prime} \cos \left(3\left(\theta-\frac{2 \pi}{7}\right)\right)+i_{d}^{\prime \prime} \cos \left(3\left(\theta-\frac{6 \pi}{7}\right)\right) \\
+i_{e}^{\prime \prime} \cos \left(3\left(\theta-\frac{8 \pi}{7}\right)\right)+i_{f}^{\prime \prime} \cos \left(3 \theta\left(-\frac{10 \pi}{7}\right)\right) \\
+i_{g}^{\prime \prime} \cos \left(3\left(\theta-\frac{12 \pi}{7}\right)\right)
\end{array}\right\} \\
i_{q 3}^{\prime \prime}=\sqrt{\frac{2}{7}}\left\{\begin{array}{c}
-i_{b}^{\prime \prime} \sin \left(3\left(\theta-\frac{2 \pi}{7}\right)\right)-i_{d}^{\prime \prime} \sin \left(3\left(\theta-\frac{6 \pi}{7}\right)\right) \\
-i_{e}^{\prime \prime} \sin \left(3\left(\theta-\frac{8 \pi}{7}\right)\right)-i_{f}^{\prime \prime} \sin \left(3\left(\theta-\frac{10 \pi}{7}\right)\right) \\
-i_{g}^{\prime \prime} \sin \left(3\left(\theta-\frac{12 \pi}{7}\right)\right)
\end{array}\right\} \\
i_{b}^{\prime \prime}+i_{d}^{\prime \prime}+i_{e}^{\prime \prime}+i_{f}^{\prime \prime}+i_{g}^{\prime \prime}=0
\end{gathered}
$$

Similarly, when phases $a$ and $d$ are open-circuited, the new phase currents are determined by solving (31-35).

$$
i_{d 1}^{\prime \prime}=\sqrt{\frac{2}{7}}\left\{\begin{array}{c}
i_{b}^{\prime \prime} \cos \left(\theta-\frac{2 \pi}{7}\right)+i_{c}^{\prime \prime} \cos \left(\theta-\frac{4 \pi}{7}\right)+i_{e}^{\prime \prime} \cos \left(\theta-\frac{8 \pi}{7}\right) \\
+i_{f}^{\prime \prime} \cos \left(\theta-\frac{10 \pi}{7}\right)+i_{g}^{\prime \prime} \cos \left(\theta-\frac{12 \pi}{7}\right)
\end{array}\right\}
$$

$i_{q 1}^{\prime \prime}=\sqrt{\frac{2}{7}}\left\{\begin{array}{c}-i_{b}^{\prime \prime} \sin \left(\theta-\frac{2 \pi}{7}\right)-i_{c}^{\prime \prime} \sin \left(\theta-\frac{4 \pi}{7}\right)-i_{e}^{\prime \prime} \sin \left(\theta-\frac{8 \pi}{7}\right) \\ -i_{f}^{\prime \prime} \sin \left(\theta-\frac{10 \pi}{7}\right)-i_{g}^{\prime \prime} \sin \left(\theta-\frac{12 \pi}{7}\right)\end{array}\right\}$

$i_{d 3}^{\prime \prime}=\sqrt{\frac{2}{7}}\left\{\begin{array}{c}i_{b}^{\prime \prime} \cos \left(3\left(\theta-\frac{2 \pi}{7}\right)\right)+i_{c}^{\prime \prime} \cos \left(3\left(\theta-\frac{4 \pi}{7}\right)\right) \\ +i_{e}^{\prime \prime} \cos \left(3\left(\theta-\frac{8 \pi}{7}\right)\right)+i_{f}^{\prime \prime} \cos \left(3 \theta\left(-\frac{10 \pi}{7}\right)\right) \\ +i_{g}^{\prime \prime} \cos \left(3\left(\theta-\frac{12 \pi}{7}\right)\right)\end{array}\right\}$

$i_{q 3}^{\prime \prime}=\sqrt{\frac{2}{7}}\left\{\begin{array}{c}-i_{b}^{\prime \prime} \sin \left(3\left(\theta-\frac{2 \pi}{7}\right)\right)-i_{c}^{\prime \prime} \sin \left(3\left(\theta-\frac{4 \pi}{7}\right)\right) \\ -i_{e}^{\prime \prime} \sin \left(3\left(\theta-\frac{8 \pi}{7}\right)\right)-i_{f}^{\prime \prime} \sin \left(3\left(\theta-\frac{10 \pi}{7}\right)\right) \\ -i_{g}^{\prime \prime} \sin \left(3\left(\theta-\frac{12 \pi}{7}\right)\right)\end{array}\right\}$

$i_{b}^{\prime \prime}+i_{c}^{\prime \prime}+i_{e}^{\prime \prime}+i_{f}^{\prime \prime}+i_{g}^{\prime \prime}=0$

\section{Numerical and experimental results}

A proposed control scheme of the drive system is presented in Fig. 3. In this structure, an offline optimization process with function fmincon determines current references to maximize the machine torques under constraints in all operation modes. Then, current references at each rotating speed $(\Omega)$ in an operation mode are stored in a look-up table. The stored current values will be selected according to the fault information and rotating speed of the rotor. Parameters of the drive system for the optimization process and experiments are shown in Table 3. The converter is supplied by a DC-bus voltage of $200 \mathrm{~V}$ and the rated RMS phase current of the 7-phase PM machine is 5.1A. Therefore, the constraints on current and voltage are carried out with $V_{\max }=100 \mathrm{~V}$ and $I_{\max }=5.1 \mathrm{~A}$.

The comparison between the proposed methods expressed in the previous section and the existing methods for seven-phase machines, such as studies in [13, 25], is necessary. As analysed in the introduction section, [13] proposes only methods for single-phase open-circuit faults while single and double-phase open-circuit faults are considered in [25]. However, the constraint on peak voltage, allowing the seven-phase machine to operate in flux- 
weakening region even in post-fault conditions, has not been considered in both papers. Although the global copper losses are minimized in [25], an unequal distribution of phase currents may lead to overrated RMS currents of certain healthy phases. To compare torques between the proposed methods and the methods in $[13,25]$ at a constant speed, all torques are generated under the same constraint on the maximum RMS current 5.1A. In addition, the back EMFs are assumed to have only the first and third harmonics in simulations. Due to the generality, methods (II) and (IV) in this study are used for the comparison. Fig. 4 shows the torque comparison at $20 \mathrm{rad} / \mathrm{s}$ with simulated results. When phase $a$ is opened, the torque created by the method presented in [13] has a high average torque (77\% of the healthy torque) and the highest torque ripples (24\%). Meanwhile, method (IV) in this paper is better with lower torque ripples (19\%) and the highest average torque (78\%). At lower values, torques by the method in [25] and method (II) are constant ( $51 \%$ and $56 \%$ of the healthy torque). It can be noted that the torque by method (II) is slightly higher than the method in [25]. When phases $a$ and $b$ are opened, the torque by the method in [25] is equal to $42 \%$ of the healthy torque while we obtain $45 \%$ with the proposed method. Therefore, these simulated results are motivational.

The proposed control strategies are verified by an experimental inverter-machine drive as shown in Fig. 5. The 7-phase machine is mechanically connected to a load drive (using a 3-phase machine) which is controlled to tune the speed of the 7-phase machine. Seven legs of IGBT are used to supply the 7-phase machine. Its switching frequency is set to $10 \mathrm{kHz}$. A dSPACE 1005 board with I/O interface is used to transfer PWM signals to the IGBT driver of the inverter and collect the measured data of speed and currents. The open-circuit fault of one phase is created safely by using an interrupting signal from a control interface. This signal helps open simultaneously 2 IGBTs of one leg of the inverter, disconnecting the machine phase to the power source.

In this section, parameters (currents, voltages, torques and powers) of the machine drive obtained from the offline optimization process are written as reference or simulated values. The parameters are used to compare with corresponding parameters in the experimental system. Experimental torques and powers are estimated values calculated from measured currents and estimated back-EMFs.

In healthy mode, the total torque is mainly generated by three harmonic components of current and back-EMF (the $1^{\text {st }}, 9^{\text {th }}$ and $3^{\text {rd }}$ harmonics). Figs. 6-8 show the current references and measured currents in rotating frames. It can be noticed that the machine currents in the rotating frames are not constant even though their references are constant. Indeed, due to the harmonics $11^{\text {th }}$ and $13^{\text {th }}$ of back-EMF which cannot be compensated by the current controllers (PI), there are current ripples in $\mathrm{d}-\mathrm{q}$ frames, resulting in torque ripples at frequency $14 \theta$. However, this torque pulsation is not significant comparing to the constant torque created by the first harmonic. A ripple-free torque can be possible by doing MTPA control strategies proposed in [37-39]. However, using MTPA strategy cannot ensure either the constraints on current and voltage or constant currents in rotating frames. Fig. 9 shows the torque-speed and power-speed characteristics in a speed range from 0 to $75 \mathrm{rad} / \mathrm{s}$ with the base speed at 37rad/s in healthy mode. The estimated total torque and power are in good accordance with the simulated values. The first (FM1), second (FM2) and third (FM3) fictitious machines contribute to the machine torque and power generations according to their proportions in the backEMF harmonic spectrum. Therefore, FM1 generates the highest torque following by FM3. At 20rad/s, before the base speed, the total machine torque and the fictitious machine torques are shown in Fig. 10. The simulated total torque is constant at $33.7 \mathrm{Nm}$ while the estimated total torque has a similar average value but $12 \%$ torque ripples at the main frequency of $14 \theta$, as previously discussed. In Fig. 11, measured phase currents always respect their constraint even in the flux-weakening region when their RMS value is fixed at 5.1A. It means that the local thermal limit of each phase is

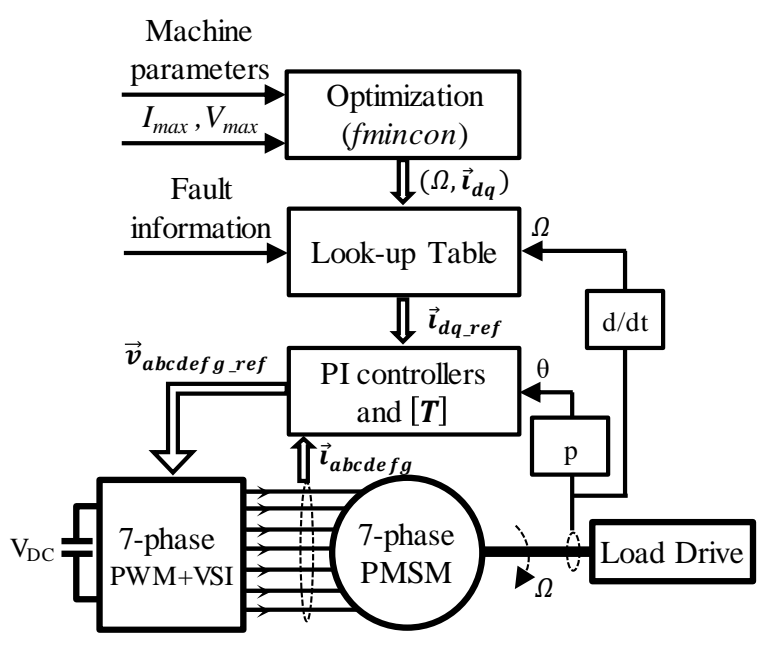

Fig. 3. Control scheme of the drive system

Table 3 Electrical parameters of the converter and machine

\begin{tabular}{lc}
\hline Parameter & Value \\
\hline Stator resistance $R(\Omega)$ & 1.4 \\
Self-inductance $L(\mathrm{mH})$ & 14.7 \\
Mutual inductance $M_{1}(\mathrm{mH})$ & 3.5 \\
Mutual inductance $M_{2}(\mathrm{mH})$ & -0.9 \\
Mutual inductance $M_{3}(\mathrm{mH})$ & -6.1 \\
Number of pole pairs $\mathrm{p}$ & 3 \\
DC-bus voltage $V_{D C}(\mathrm{~V})$ & 200 \\
Maximum peak current of VSI (A) & 15 \\
Rated RMS current of 7-phase PMSM (A) & 5.1 \\
\hline
\end{tabular}

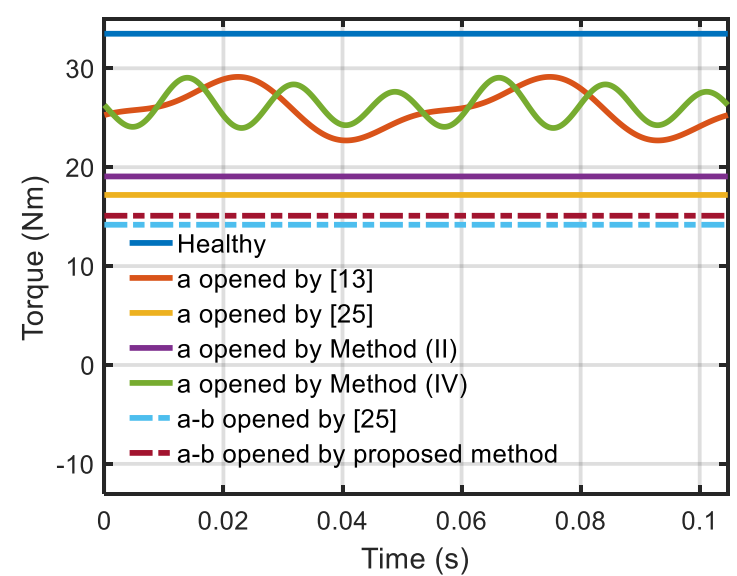

Fig. 4. (Simulated results) Torque comparison at 20rad/s with existing methods under the same constraint on maximum RMS phase current (5.1A) 


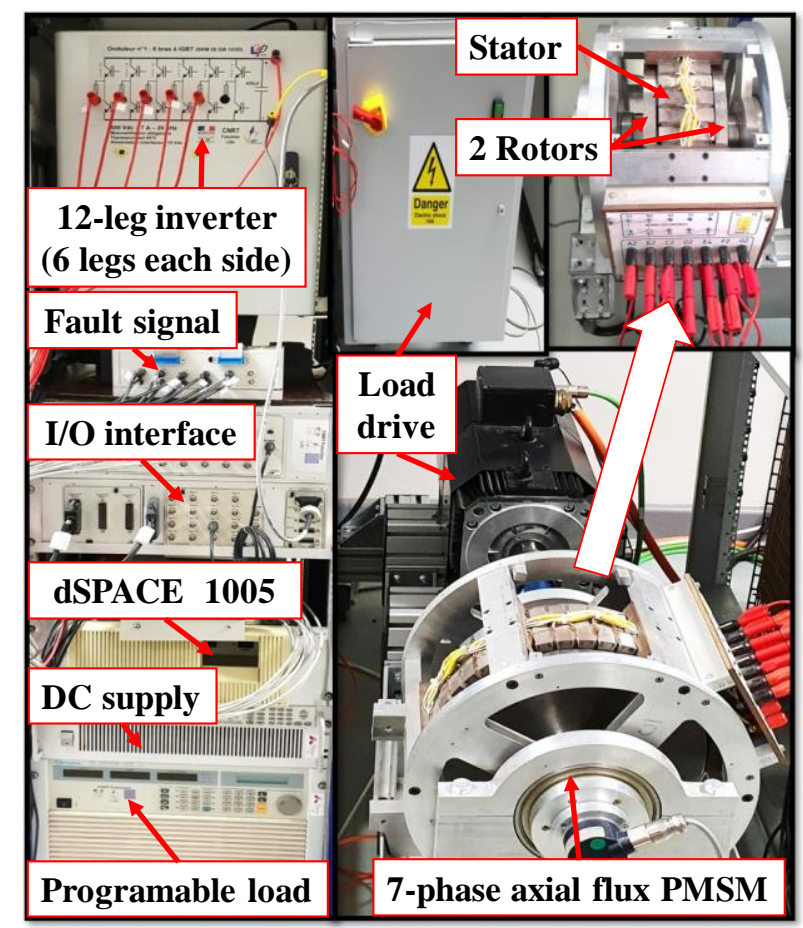

Fig. 5. Experimental test bench of the drive system

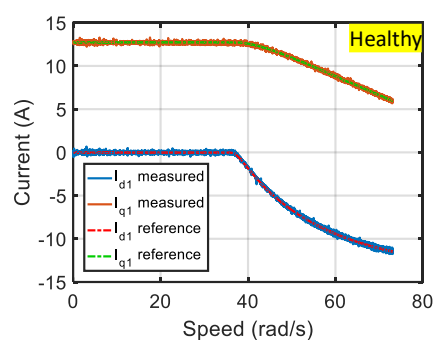

$a$

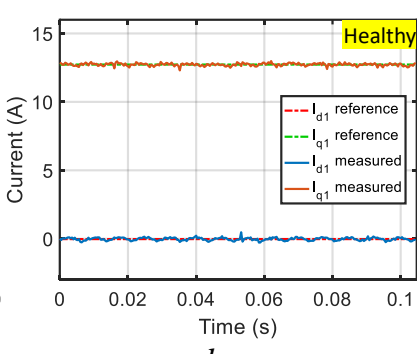

$b$
Fig. 6. (Experimental results) Currents in $\left(d_{1}-q_{1}\right)$ frame in healthy mode

(a) Currents vs speed, (b) Currents vs time at $20 \mathrm{rad} / \mathrm{s}$

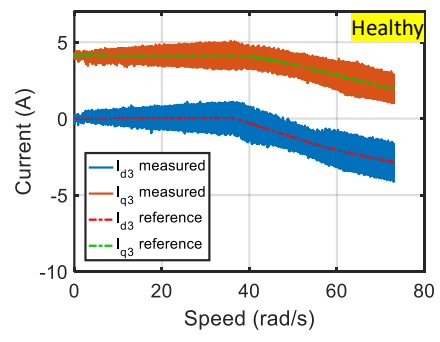

$a$

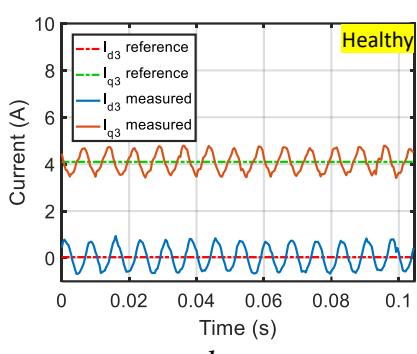

$b$
Fig. 7. (Experimental results) Currents in $\left(d_{3}-q_{3}\right)$ frame in healthy mode

(a) Currents vs speed, (b) Currents vs time at $20 \mathrm{rad} / \mathrm{s}$

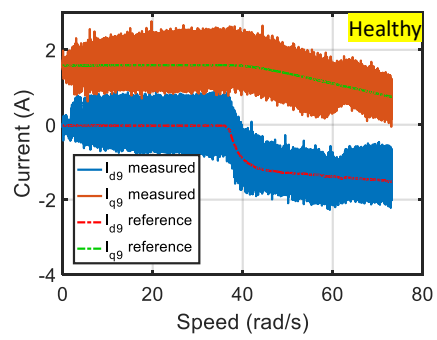

$a$

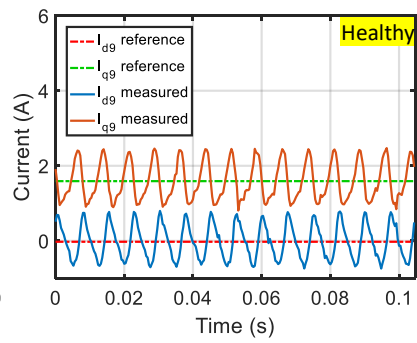

$b$
Fig. 8. (Experimental results) Currents in $\left(d_{9}-q_{9}\right)$ frame in healthy mode

(a) Currents vs speed, (b) Currents vs time at $20 \mathrm{rad} / \mathrm{s}$

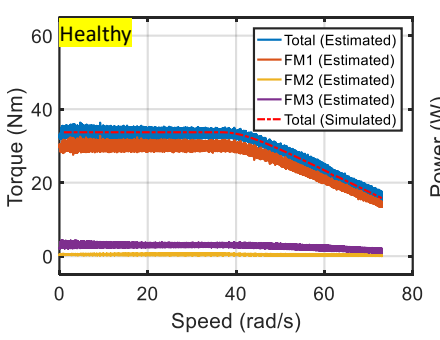

$a$

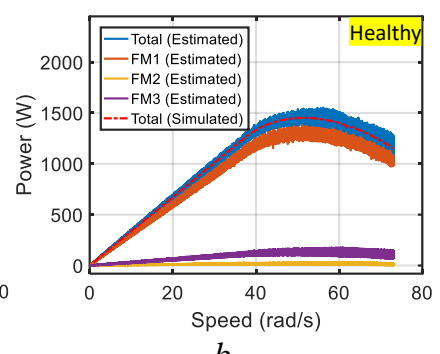

b
Fig. 9. (Experimental results) Torques and powers vs speed in healthy mode

(a) Torques vs speed, (b) Powers vs speed

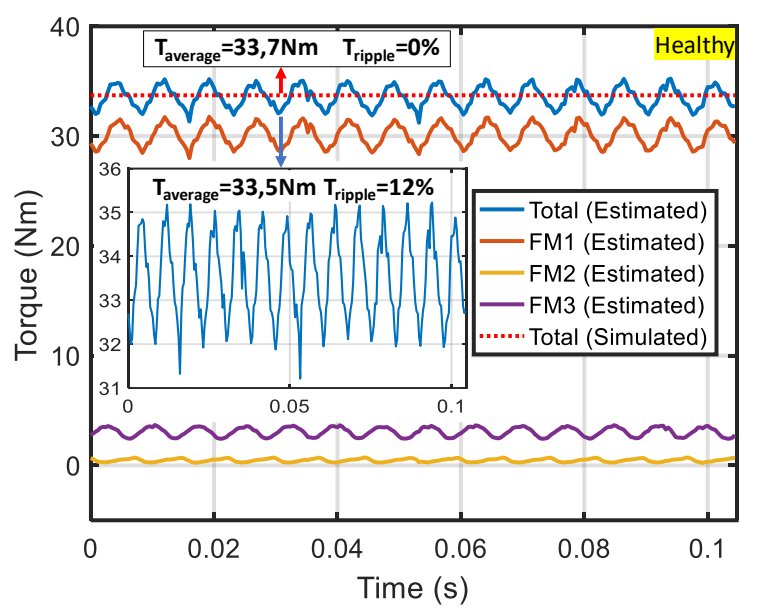

Fig. 10. (Experimental results) Torques vs time in healthy mode at $20 \mathrm{rad} / \mathrm{s}$

guaranteed in the speed range. Similarly, Fig. 12 shows that experimental voltage references, output signals of current controllers in experimental tests, reach their limit $\left(\mathrm{V}_{\max }=100 \mathrm{~V}\right)$ at the base speed and within their limit at high speeds. Figs. 11-12 also show changes in the waveforms of measured currents and voltage references before and after the base speed (at 20rad/s and 47rad/s).

When phase $a$ is opened, the measured phase currents using current references of healthy mode (without new current references) at 20 rad $/ \mathrm{s}$ are shown in Fig. 13. Phase $e$ has the highest RMS current at $7.9 A$, exceeding its rated value. Simultaneously, the torque ripples increase extremely from $12 \%$ (pre-fault) to 50\% (post-fault) as shown in Fig. 14. From the reasons above, it is necessary to impose new current references to the machine. In Fig. 14 and Table 4, four methods (I-IV) are compared in terms of torque generation, the highest RMS phase currents and the highest peak phase voltage references at 20rad/s. Estimated average torques (experimental values) by the four methods are in good accordance with the simulated torques. Method (I) produces an average torque equal to about $56 \%$ of the healthy mode while that of method (II) is slightly higher at about $57 \%$. Methods (III) and (IV) give higher average torques equal to approximately $77 \%$ and $78 \%$ of the healthy torque, respectively. It is worth noting that the third harmonic currents in methods (II) and (IV) do not contribute much to average torques, which differs from results in [31]. The reason is that the presence of third harmonic current leads to a decrease in the first harmonic current to respect the constraint on RMS current. Thus, the torque produced by the first harmonic current slightly decreases while the torque created by the third harmonic current cannot compensate. 


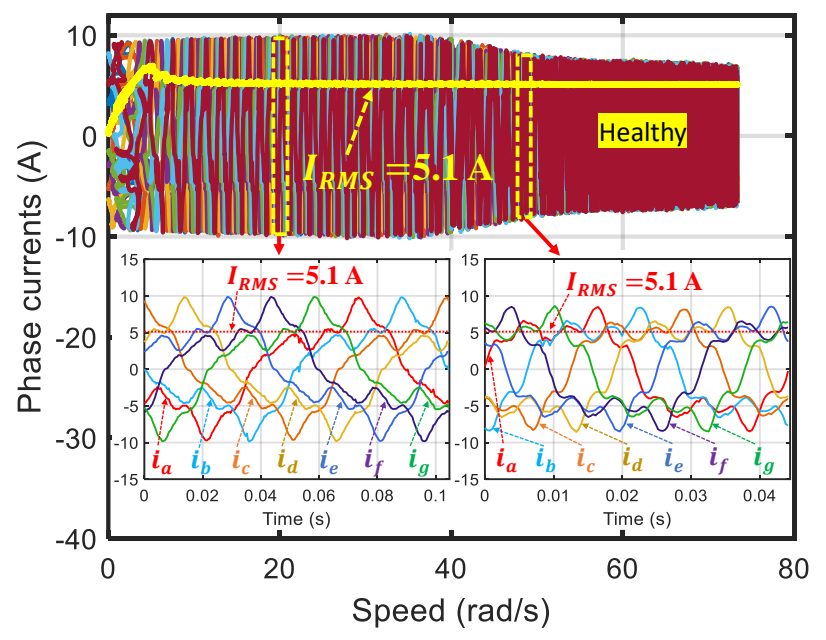

Fig. 11. (Experimental results) Phase currents in the speed range in healthy mode, and their waveforms at 20rad/s and $47 \mathrm{rad} / \mathrm{s}$

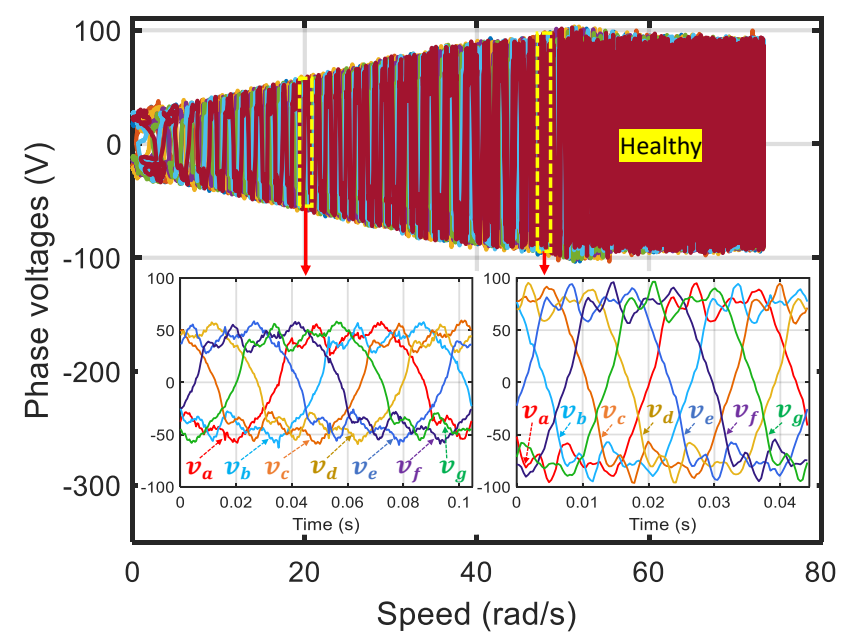

Fig. 12. (Experimental results) Voltage references in the speed range in healthy mode, and their waveforms at 20rad/s and $47 \mathrm{rad} / \mathrm{s}$

In Table 4, with simulated results from the offline optimization, by considering only the first and third harmonics of back-EMF in faulty modes, torques of methods (I) and (II) are constant since constant current references in $\mathrm{d}-\mathrm{q}$ frames are imposed. On the contrary, methods (III-IV) with time-variant currents in rotating frames generate torque pulsations of $24 \%$ and $19 \%$, respectively. The simulated torque ripples in method (IV) are slightly lower than method (III) due to the compensation of torque ripples when the third harmonic of current interacts with all harmonics of backEMF. In experimental tests, the estimated torque ripples by four proposed methods are non-zero and significantly higher than the simulated values. The main reason is the interaction between the existing ninth harmonic of back-EMF in the experimental machine with the ninth harmonic of current in all methods, causing more torque ripples. Experimental torques by methods (III-IV) have slightly lower pulsations than (I-II) because of their higher average torques. From Table 4, at 20rad/s, the simulated and measured values of the highest RMS phase currents by the proposed methods are always equal or less than their limit (5.1A). The experimental values of the voltage references are higher than the simulated

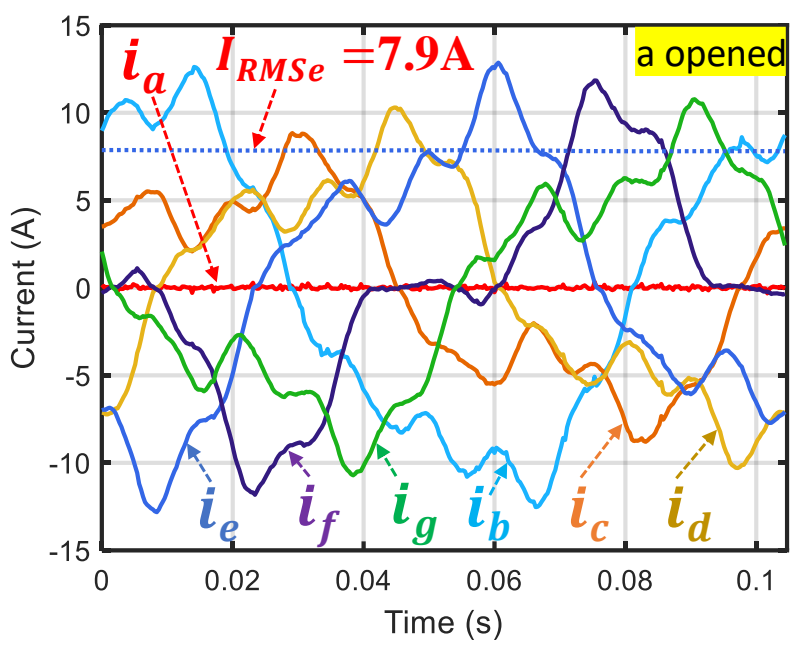

Fig. 13. (Experimental results) Currents at 20rad/s when phase a is opened without new current references

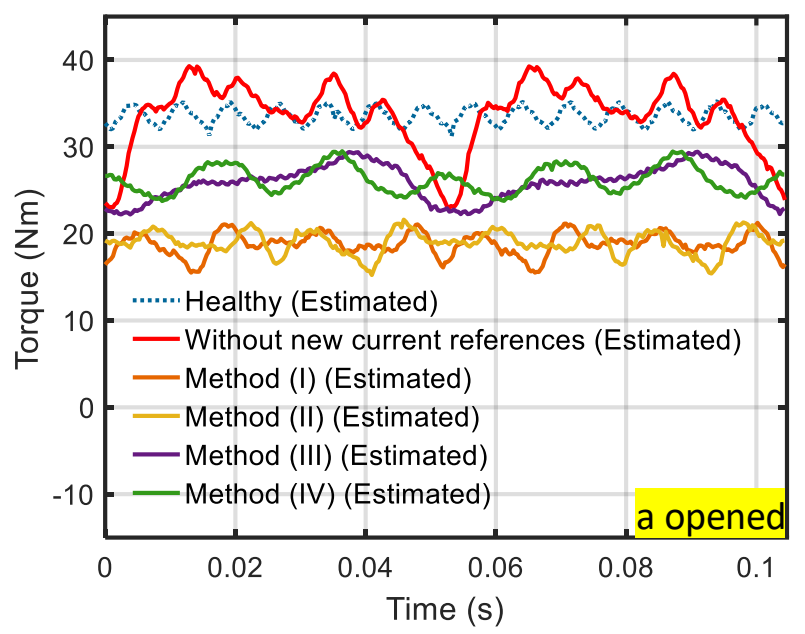

Fig. 14. (Experimental results) Torques at 20rad/s when phase a is opened in different cases

values because of the presence of high frequency components of the experimental back-EMF, and due to errors of current controllers, which create more voltage references.

In post-fault operation without reconfiguration at $20 \mathrm{rad} / \mathrm{s}$, the highest values of voltage references increase dramatically from $59 \mathrm{~V}$ to $90 \mathrm{~V}$. Thanks to four methods (IIV), these values are reduced significantly to avoid the inverter voltage saturation. The waveforms of measured phase currents at low speed $(20 \mathrm{rad} / \mathrm{s})$ by the 4 proposed methods are shown in Fig. 15. Measured currents of the remaining healthy phases using methods (I-II) have different waveforms and amplitudes. Only one phase has the RMS current approximately equal to the current limit. Using methods (III-IV) allows currents in all phases to have similar waveforms, resulting in equally distributed copper losses. Thus, methods (III-IV) have higher efficiencies than methods (I-II) at low speeds.

The capability of the drive system in terms of speed range is reduced when an open-circuit fault happens as shown in Figs. 16 and 17. Specifically, the speed range reduces from $75 \mathrm{rad} / \mathrm{s}$ (pre-fault) to $61 \mathrm{rad} / \mathrm{s}$ with methods (I-II). Methods 
Table 4 Average torques in healthy mode $T_{a v_{-} h m}$, in faulty mode $T_{a v_{-} f m}$, torque ripples $T_{\text {rip }}$ and constraints when phase $a$ is opened at $20 \mathrm{rad} / \mathrm{s}$

\begin{tabular}{|c|c|c|c|c|c|c|c|c|}
\hline \multirow[t]{2}{*}{ Mode } & \multicolumn{2}{|c|}{$\frac{T_{a v_{-} f m}}{T_{a v_{-} h m}}(\%)$} & \multicolumn{2}{|c|}{$T_{\text {rip }}(\%)$} & \multicolumn{2}{|c|}{$\begin{array}{l}\text { Highest } \\
\mathrm{I}_{\mathrm{RMS}}(\mathrm{A})\end{array}$} & \multicolumn{2}{|c|}{$\begin{array}{l}\text { Highest } \\
V_{\text {peak }}(V)\end{array}$} \\
\hline & (1) & (2) & (1) & (2) & (1) & $(2)$ & (1) & (2) \\
\hline Healthy mode & -- & -- & 0 & 12 & 5.1 & 5.1 & 45 & 59 \\
\hline $\begin{array}{l}\text { Without new } \\
\text { currents }\end{array}$ & -- & 100.2 & -- & 50 & -- & 7.9 & -- & 90 \\
\hline Method (I) & 55.9 & 56.1 & 0 & 30 & 5.1 & 5 & 40 & 58 \\
\hline Method (II) & 56.5 & 56.6 & 0 & 33 & 5.1 & 5 & 41 & 59 \\
\hline Method (III) & 77.2 & 76.9 & 24 & 29 & 5.1 & 5.1 & 42 & 57 \\
\hline Method (IV) & 78.2 & 77.9 & 19 & 25 & 5.1 & 5.1 & 49 & 62 \\
\hline
\end{tabular}

(1) Simulated values (2) Experimental values

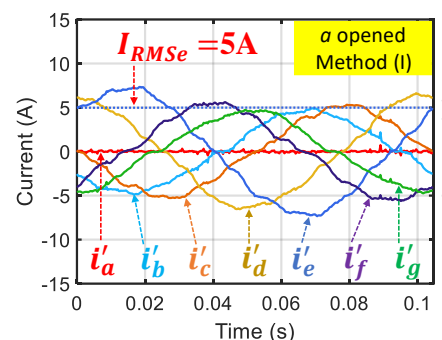

$a$

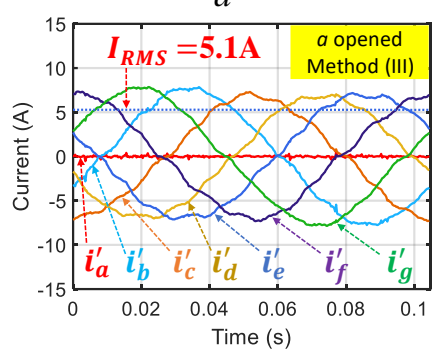

$c$

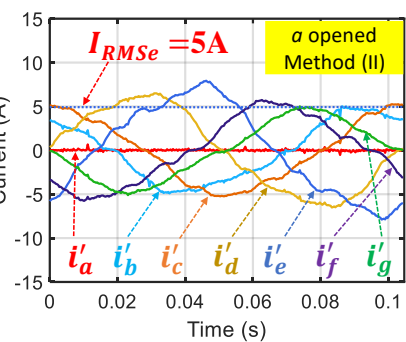

$b$

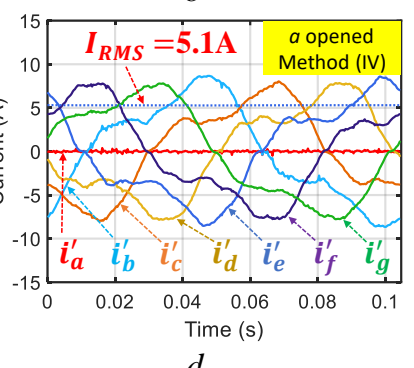

$d$
Fig. 15. (Experimental results) Measured phase currents at $20 \mathrm{rad} / \mathrm{s}$ with the proposed methods when phase a is opened (a) Method (I), (b) Method (II), (c) Method (III), (d) Method (IV)

(III-IV) have a maximum speed of $50 \mathrm{rad} / \mathrm{s}$, lower than methods (I-II), due to a decrease in amplitude of current references in the flux-weakening region to avoid high torque ripples [36]. Therefore, in single-phase open-circuit faults, methods (III-IV) are preferable at low speeds while methods (I-II) should be used at high speeds. Furthermore, the constraints on RMS current and peak voltage are strictly respected at all speeds in all modes. For instance, Fig. 18 shows the phase currents by method (II) and phase voltage references by method (IV).

In double-phase open-circuit faults, the experiments are carried out with the faults happen in two adjacent phases ( $a$ $b)$ and two non-adjacent phases $(a-c$ and $a-d)$. The control strategies applied for the three cases of double-phase opencircuit faults are similar, as presented in section 3. When phases $a$ and $b$ are opened, the measured phase currents at 20rad/s before and after imposing new current references are shown in Fig. 19. The highest RMS phase current reduces from $8 \mathrm{~A}$ to $5 \mathrm{~A}$, respecting the current limit. The current waveforms of all phases are different, like the cases of methods (I-II) in single-phase open-circuit faults. In Fig. 20, the estimated torque ripples reduce from $81 \%$ to $45 \%$ in the post-fault operation when new current references are injected.

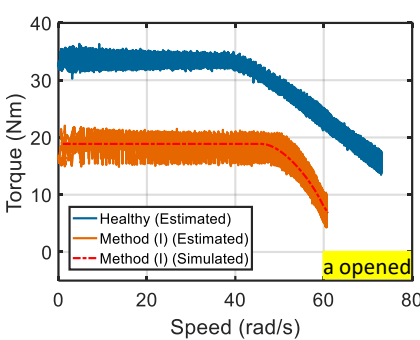

$a$

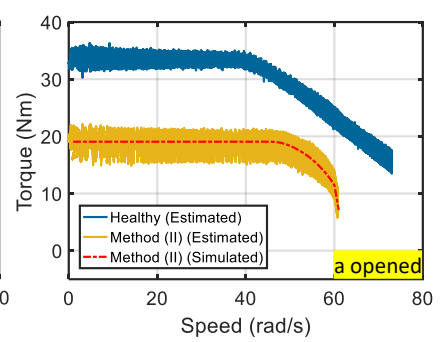

$b$
Fig. 16. (Experimental results) Torques vs speed with the proposed methods when phase a is opened

(a) Method (I), (b) Method (II)

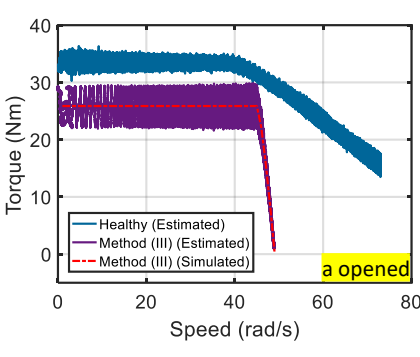

$a$

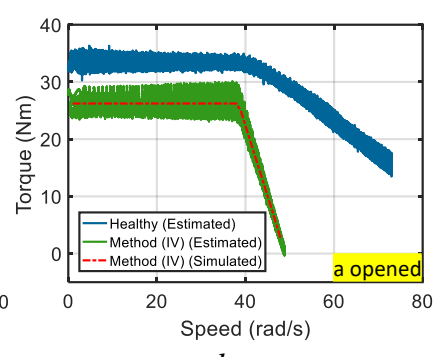

$b$
Fig. 17. (Experimental results) Torques vs speed with proposed methods when phase a is opened

(a) Method (III), (b) Method (IV)

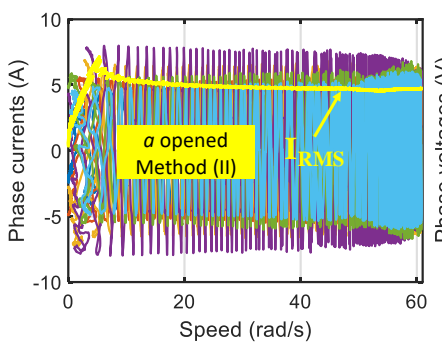

$a$

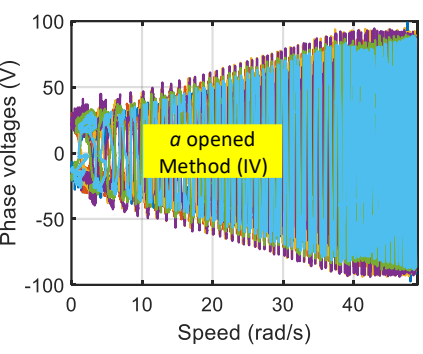

$b$
Fig. 18. (Experimental results) Parameters in the speed range with the proposed methods when phase a is opened (a) Phase currents by method (II), (b) Voltage references by method (IV)
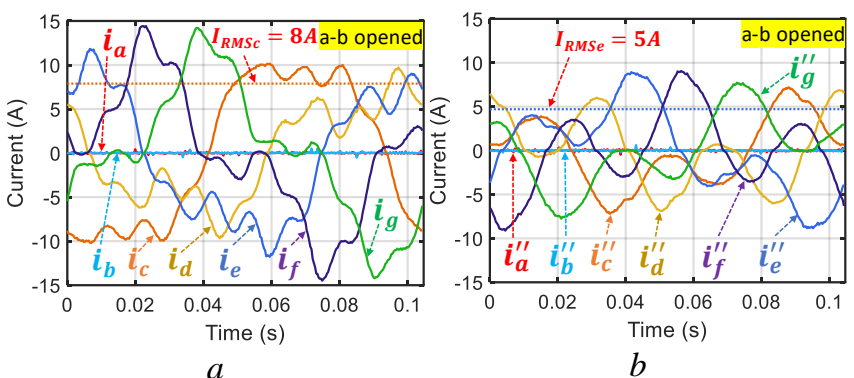

Fig. 19. (Experimental results) Phase currents at 20rad/s when phases $(a-b)$ are opened

(a) Without new current references, (b) Using new current references

Although only two phases over seven phases are opencircuited, the average torques decrease more than $50 \%$ due to the constraints on current and voltage. The operation in terms of the speed range with open-circuit faults in phases $(a-b)$ is experimentally tested with a maximum speed of 59rad/s as shown in Figs. 21 and 22. Performances for the other doublephase open-circuit faults are like the case of open-circuit fault in phases $(a-b)$. For example, Fig. 23 shows the torquespeed characteristics when phases $(a-c)$ and $(a-d)$ are opened. 


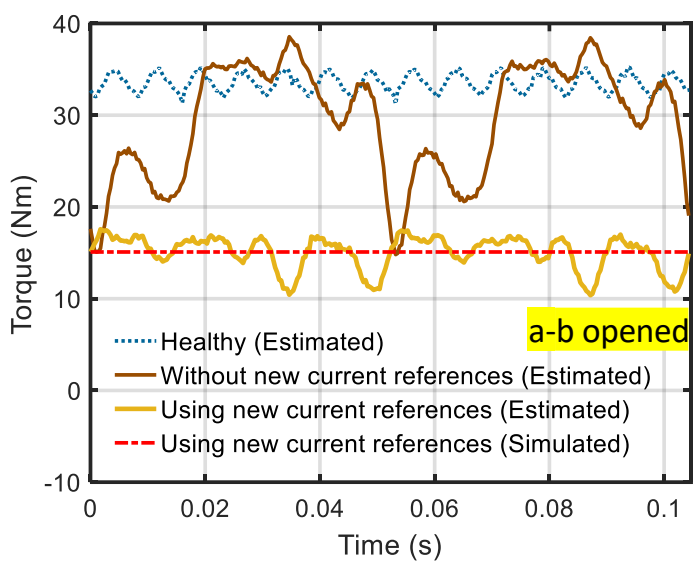

Fig. 20. (Experimental results) Torques at 20rad/s when phases $(a-b)$ are opened

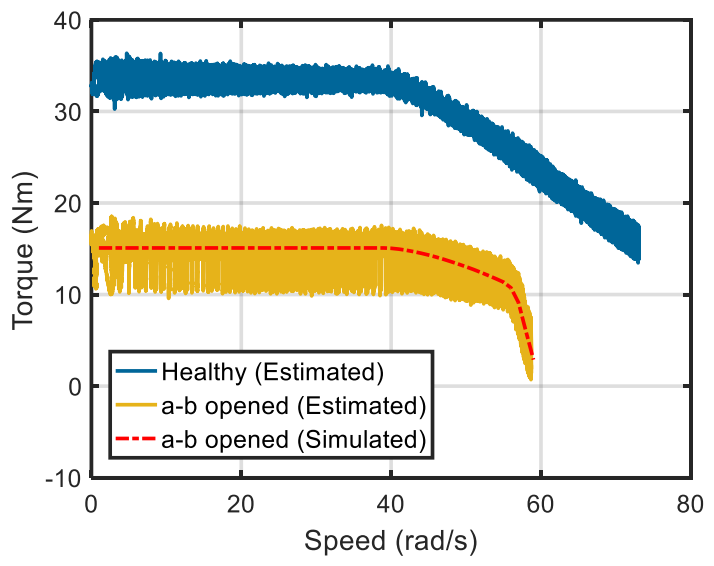

Fig. 21. (Experimental results) Torques vs speed when phases $(a-b)$ are opened

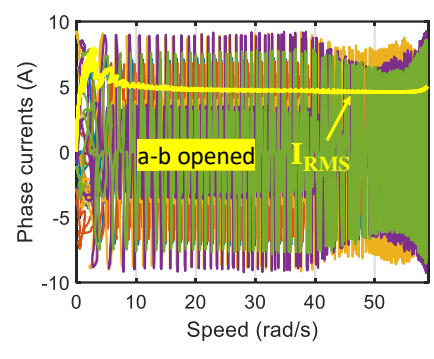

$a$

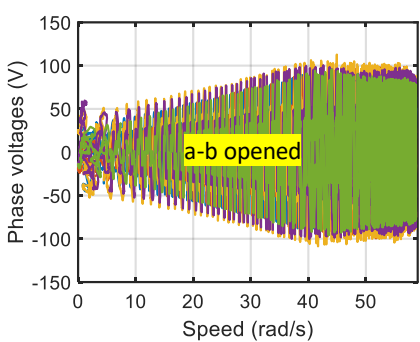

$b$
Fig. 22. (Experimental results) Currents and voltage references in the speed range with new current references when $(a-b)$ are opened

(a) Phase currents, (b) Phase voltage references

Table 5 gives a summary of the copper losses at 20 $\mathrm{rad} / \mathrm{s}$ in healthy and all faulty modes. By using the proposed methods, the copper losses per phase and global copper losses in post-fault conditions do not exceed the corresponding values in healthy mode $(36.4 \mathrm{~W}$ per phase and $254.9 \mathrm{~W}$ in total). In single-phase open-circuit faults, methods (III) and (IV) have the highest global copper losses because of identical RMS phase currents. Methods (I) and (II) result in different copper losses in machine phases in which the highest loss is slightly less than in healthy mode. Similarly, the copper losses in the three cases of double-phase open-circuited faults $(a-b, a$ $c$, and $a-d$ ) are less than the copper losses in healthy mode and in single-phase open-circuit modes. In faulty modes, it is possible to impose the same global copper losses as in healthy mode, but this will lead to a higher copper loss per phase.

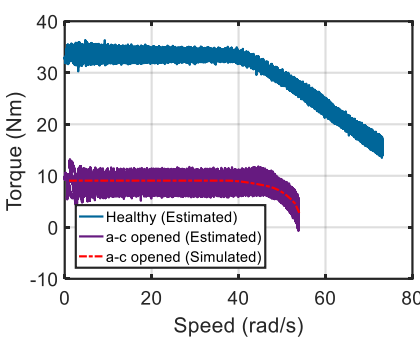

$a$

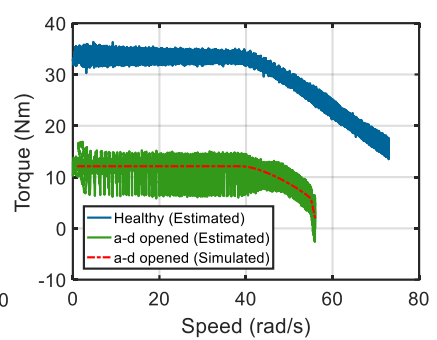

$b$
Fig. 23. (Experimental results) Torques vs speed with new current references in double-phase open-circuit faults (a) Phases $(a-c)$ are opened, (b) Phases $(a-d)$ are opened

Table 5 Copper losses in healthy and faulty modes at $20 \mathrm{rad} / \mathrm{s}$

\begin{tabular}{lcc}
\hline Mode & $\begin{array}{c}\text { Copper loss } \\
\text { per phase (W) }\end{array}$ & $\begin{array}{c}\text { Global copper loss } \\
(\mathrm{W})\end{array}$ \\
\hline Healthy & 36.4 & 254.9 \\
$a$ opened Method (I) & $35^{(*)}$ & 127.6 \\
$a$ opened Method (II) & $35^{(*)}$ & 127.7 \\
$a$ opened Method (III) & 36.4 & 218.5 \\
$a$ opened Method (IV) & 36.4 & 218.5 \\
$(a-b)$ opened & $34^{(*)}$ & 120.4 \\
$(a-c)$ opened & $33^{(*)}$ & 100.5 \\
$(a-d)$ opened & $34^{(*)}$ & 115.7 \\
\hline
\end{tabular}

(*) The copper loss of the phase having the highest RMS current

\section{Conclusions}

The paper has proposed control strategies for a multiphase (>7) PMSM drive in healthy and open-circuit modes. Thanks to the offline optimization and experimental verification, the machine with non-sinusoidal back-EMFs works properly with optimal torques, including the fluxweakening operation. The constraints on copper loss (according to the thermal limit per phase) and peak voltage are strictly respected. The proposed methods can be applied to machines with a higher number of phases. In healthy mode, three harmonics of current are chosen to generate torque. In single-phase open-circuit faults, by imposing constant currents in rotating frames $\left(\mathrm{d}_{1}-\mathrm{q}_{1}\right)$ and $\left(\mathrm{d}_{3}-\mathrm{q}_{3}\right)$ based on methods (I-II), it is simple to control the machine. However, currents in the other rotating frame $\left(\mathrm{d}_{9}-\mathrm{q}_{9}\right)$ are time-variant and must be tracked properly to reduce torque ripples. Using methods (I-II) cannot have the same copper loss per phase. With methods (III-IV), since the currents are imposed in natural frame, we can expect that they have the same amplitude and waveform, resulting in the same copper loss per phase. Methods (III-IV) can be used at low speeds due to their high torques but a low speed range, meanwhile, methods (I-II) are suitable for high speeds because of their larger speed range.

\section{References}

[1] Levi, E.: 'Multiphase Electric Machines for Variable-Speed Applications', IEEE Transactions on Industrial Electronics, 2008, 55, (5), pp. 1893-1909.

[2] Levi, E., Bojoi, R., Profumo, F., et al.: 'Multiphase Induction Motor Drives - a Technology Status Review', IET Electric Power Applications, 2007, 1, (4), pp. 489-516.

[3] Barrero, F. and Duran, M.J.: 'Recent Advances in the Design, Modeling, and Control of Multiphase Machines Part I', IEEE Transactions on Industrial Electronics, 2016, 63, (1), pp. 449-458.

[4] Duran, M.J. and Barrero, F.: 'Recent Advances in the Design, Modeling, and Control of Multiphase Machines Part II', IEEE Transactions on Industrial Electronics, 2016, 63, (1), pp. 459-468. 
[5] Trabelsi, M., Nguyen, N.K., and Semail, E.: 'Real-Time Switches Fault Diagnosis Based on Typical Operating Characteristics of FivePhase Permanent-Magnetic Synchronous Machines', IEEE Transactions on Industrial Electronics, 2016, 63, (8), pp. 4683-4694.

[6] Trabelsi, M., Semail, E., and Nguyen, N.K.: 'Experimental Investigation of Inverter Open-Circuit Fault Diagnosis for Biharmonic Five-Phase Permanent Magnet Drive', IEEE Journal of Emerging and Selected Topics in Power Electronics, 2018, 6, (1), pp. 339-351.

[7] Semail, E., Bouscayrol, A., and Hautier, J.P.: 'Vectorial Formalism for Analysis and Design of Polyphase Synchronous Machines', Eur. Phys. J. AP, 2003, 22, (3), pp. 207-220.

[8] Refaie, A.M.E.-. 'Fractional-Slot Concentrated-Windings Synchronous Permanent Magnet Machines: Opportunities and Challenges', IEEE Transactions on Industrial Electronics, 2010, 57, (1), pp. 107-121.

[9] Boglietti, A., El-Refaie, A.M., Drubel, O., et al.: 'Electrical Machine Topologies: Hottest Topics in the Electrical Machine Research Community', IEEE Industrial Electronics Magazine, 2014, 8, (2), pp. 18-30.

[10] Dajaku, G. and Gerling, D.: 'Opportunities of Advanced Multi-Phase Concentrated Windings'. Proc. 13th International Conference on Electrical Machines (ICEM), Alexandroupoli, Greece, 3-6 Sept. 2018, pp. 325-331.

[11] Bojoi, R., Rubino, S., Tenconi, A., et al.: 'Multiphase Electrical Machines and Drives: A Viable Solution for Energy Generation and Transportation Electrification'. Proc. International Conference and Exposition on Electrical and Power Engineering (EPE), Iasi, Romania, 20-22 Oct. 2016, pp. 632-639.

[12] Burkhardt, Y., Spagnolo, A., Lucas, P., et al.: 'Design and Analysis of a Highly Integrated 9-Phase Drivetrain for EV Applications'. Proc. 2014 International Conference on Electrical Machines (ICEM), Berlin, Germany, 2-5 Sept. 2014, pp. 450-456.

[13] Jen-Ren, F. and Lipo, T.A.: 'Disturbance-Free Operation of a Multiphase Current-Regulated Motor Drive with an Opened Phase', IEEE Transactions on Industry Applications, 1994, 30, (5), pp. 12671274.

[14] Fall, O., Nguyen, N.K., Charpentier, J.F., et al.: 'Variable Speed Control of a 5-Phase Permanent Magnet Synchronous Generator Including Voltage and Current Limits in Healthy and Open-Circuited Modes', Electric Power Systems Research, 2016, 140, pp. 507-516.

[15] Hyung-Min, R., Ji-Woong, K., and Seung-Ki, S.: 'Synchronous-Frame Current Control of Multiphase Synchronous Motor under Asymmetric Fault Condition Due to Open Phases', IEEE Transactions on Industry Applications, 2006, 42, (4), pp. 1062-1070.

[16] Guzmán, H., Durán, M.J., and Barrero, F.: 'A Comprehensive Fault Analysis of a Five-Phase Induction Motor Drive with an Open Phase'. Proc. 15th International Power Electronics and Motion Control Conference (EPE/PEMC), Novi Sad, Serbia, 4-6 Sept. 2012, pp. LS5b.3-1-LS5b.3-6.

[17] Guzman, H., Duran, M.J., Barrero, F., et al.: 'Comparative Study of Predictive and Resonant Controllers in Fault-Tolerant Five-Phase Induction Motor Drives', IEEE Transactions on Industrial Electronics, 2016, 63, (1), pp. 606-617.

[18] Tian, B., An, Q.T., Duan, J.D., et al.: 'Cancellation of Torque Ripples with FOC Strategy under Two-Phase Failures of the Five-Phase PM Motor', IEEE Transactions on Power Electronics, 2017, 32, (7), pp. 5459-5472.

[19] Tian, B., An, Q.T., Duan, J.D., et al.: 'Decoupled Modeling and Nonlinear Speed Control for Five-Phase PM Motor under SinglePhase Open Fault', IEEE Transactions on Power Electronics, 2017, 32, (7), pp. 5473-5486.

[20] Zhou, H., Zhao, W., Liu, G., et al.: 'Remedial Field-Oriented Control of Five-Phase Fault-Tolerant Permanent-Magnet Motor by Using Reduced-Order Transformation Matrices', IEEE Transactions on Industrial Electronics, 2017, 64, (1), pp. 169-178.

[21] Liu, G., Lin, Z., Zhao, W., et al.: 'Third Harmonic Current Injection in Fault-Tolerant Five-Phase Permanent-Magnet Motor Drive', IEEE Transactions on Power Electronics, 2018, 33, (8), pp. 6970 - 6979.

[22] Dwari, S. and Parsa, L.: 'Fault-Tolerant Control of Five-Phase Permanent-Magnet Motors with Trapezoidal Back EMF', IEEE Transactions on Industrial Electronics, 2011, 58, (2), pp. 476-485.

[23] Mohammadpour, A. and Parsa, L.: 'A Unified Fault-Tolerant Current Control Approach for Five-Phase PM Motors with Trapezoidal Back EMF under Different Stator Winding Connections', IEEE Transactions on Power Electronics, 2013, 28, (7), pp. 3517-3527.

[24] Dwari, S. and Parsa, L.: 'Open-Circuit Fault Tolerant Control of FivePhase Permanent Magnet Motors with Third-harmonic Back-EMF'.
Proc. 34th Annual Conference of IEEE Industrial Electronics, Orlando, FL, USA, 10-13 Nov. 2008, pp. 3114-3119.

[25] Locment, F., Semail, E., and Kestelyn, X.: 'Vectorial Approach-Based Control of a Seven-Phase Axial Flux Machine Designed for Fault Operation', IEEE Transactions on Industrial Electronics, 2008, 55, (10), pp. 3682-3691.

[26] Che, H.S., Duran, M.J., Levi, E., et al.: 'Postfault Operation of an Asymmetrical Six-Phase Induction Machine with Single and Two Isolated Neutral Points', IEEE Transactions on Power Electronics, 2014, 29, (10), pp. 5406-5416.

[27] Munim, W.N.W.A., Che, H.S., and Hew, W.P.: 'Fault Tolerant Capability of Symmetrical Multiphase Machines under One OpenCircuit Fault'. Proc. 4th IET Clean Energy and Technology Conference (CEAT 2016), Kuala Lumpur, Malaysia, 14-15 Nov. 2016, pp. 1-6.

[28] Sun, Z., Wang, J., Jewell, G.W., et al.: 'Enhanced Optimal Torque Control of Fault-Tolerant PM Machine under Flux-Weakening Operation', IEEE Transactions on Industrial Electronics, 2010, 57, (1), pp. 344-353

[29] Bermudez, M., Gomozov, O., Kestelyn, X., et al.: 'Model Predictive Optimal Control Considering Current and Voltage Limitations: RealTime Validation Using Opal-RT Technologies and Five-Phase Permanent Magnet Synchronous Machines', Mathematics and Computers in Simulation, 2019, 158, pp. 148-161.

[30] Lu, H., Li, J., Qu, R., et al.: 'Fault-Tolerant Predictive Current Control with Two-Vector Modulation for Six-Phase Permanent Magnet Synchronous Machine Drives', IET Electric Power Applications, 2018, 12, (2), pp. 169-178

[31] Vu, D.T., Nguyen, N.K., Semail, E., et al.: 'Torque Optimization of Seven-Phase BLDC Machines in Normal and Degraded Modes with Constraints on Current and Voltage'. Proc. The 9th International Conference on Power Electronics, Machines and Drives, Liverpool, UK, 4/2018.

[32] Locment, F., Semail, E., and Kestelyn, X.: 'Optimum Use of DC Bus by Fitting the Back-Electromotive Force of a 7-Phase Permanent Magnet Synchronous Machine'. Proc. European Conference on Power Electronics and Applications, Dresden, Germany, 11-14 Sept. 2005, pp. pp.1-9.

[33] Locment, F., Semail, E., and Piriou, F.: 'Design and Study of a Multiphase Axial-Flux Machine', IEEE Transactions on Magnetics, 2006, 42, (4), pp. 1427-1430.

[34] Semail, E., Kestelyn, X., and Bouscayrol, A.: 'Right Harmonic Spectrum for the Back-Electromotive Force of an N-Phase Synchronous Motor'. Proc. the 39th IEEE Industry Applications Conference, Seattle, WA, USA, 3-7 Oct. 2004, pp. 71-78.

[35] Toliyat, H.A.: 'Analysis and Simulation of Five-Phase Variable-Speed Induction Motor Drives under Asymmetrical Connections', IEEE Transactions on Power Electronics, 1998, 13, (4), pp. 748-756.

[36] Vu, D.T., Nguyen, N.K., and Semail, E.: 'Sensitivity of Torque Control for Seven-Phase BLDC Machine with One Opened Phase under Constraints on Voltage and Current'. Proc. International Symposium on Power Electronics, Electrical Drives, Automation and Motion (SPEEDAM), Amalfi, Italy, 20-22 June 2018, pp. 142-148.

[37] Dwari, S. and Parsa, L.: 'An Optimal Control Technique for Multiphase PM Machines under Open-Circuit Faults', IEEE Transactions on Industrial Electronics, 2008, 55, (5), pp. 1988-1995.

[38] Kestelyn, X. and Semail, E.: 'A Vectorial Approach for Generation of Optimal Current References for Multiphase Permanent-Magnet Synchronous Machines in Real Time', IEEE Transactions on Industrial Electronics, 2011, 58, (11), pp. 5057-5065.

[39] Flieller, D., Nguyen, N.K., Wira, P., et al.: 'A Self-Learning Solution for Torque Ripple Reduction for Nonsinusoidal Permanent-Magnet Motor Drives Based on Artificial Neural Networks', IEEE Transactions on Industrial Electronics, 2014, 61, (2), pp. 655-666. 